\title{
"Solo Dios sabe que ellos no saben lo que hacen": Un análisis a la locura criminal en los años de 1809 y 1822
}

"Solo Dios sabe que ellos no saben lo que hacen": an analysis of criminal madness in 1809 and 1822

\section{Juan Camilo Epe Narváez*}

\section{Resumen}

Los locos siempre han sido parte del paisaje común de las sociedades, su figura siempre ha estado presente en las calles, las casas, los mercados y otros espacios públicos. Estos sujetos han sido reconocidos por sus actos disímiles a la honorabilidad y las buenas costumbres, mayormente cuando se han visto comprometidos en actos delictivos. El objetivo de este artículo es ofrecerle al lector la percepción social de los testigos que estuvieron presentes en los actos criminales de Roque Londoño y Lucía Ardila, dos locos pertenecientes a la parroquia de La Mesa y la ciudad de Vélez en los años de 1809 y 1822. Además, a lo largo del trabajo se analizará la visión social de la locura durante el siglo XVIII e inicios del XIX, al igual que el concepto de delito, esto con la intención de conocer la unión que existió entre estos dos aspectos que desatarían una profunda estigmatización sobre los sujetos locos.

Palabras clave: Locura, criminal, delitos, pobres.

\begin{abstract}
Madmen have always been part of the common landscape of societies, their figure has always been present in the streets, houses, markets and other public spaces. These subjects have been recognized for their actions dissimilar to good repute and morality, mostly when they have been involved in criminal acts. The objective of this article is to offer the reader the social perception of the witnesses who were present in the criminal acts of Roque Londoño and Lucia Ardila, two madmen belonging to the parish of La Mesa and the city of Velez in the years 1809 and 1822. In addition, throughout the work will be analyzed the social vision of madness $d u$ ring the eighteenth century and the early $n i-$ neteenth, as well as the concept of crime, this will have the intention of knowing the union that existed between these two aspects that would unleash a deep stigmatization on the mad subjects.
\end{abstract}

Keywords: Madness, criminal, crimes, poor people.

Para citar el artículo: Epe Narváez, Juan Camilo. "Solo Dios sabe que ellos no saben lo que hacen': un análisis a la locura criminal en los años de 1809 y 1822 ". Revista Artificios, n. ${ }^{\circ} 17$ (2020): 70-89.

Fecha de recepción: 25 de mayo de 2020

Fecha de aceptación: 12 de agosto de 2020

\footnotetext{
* Historiador de la Universidad del Valle, Colombia. Correo electrónico: camiloepe06@gmail.com 


\section{Introducción}

La imagen de locura que presentaremos en este trabajo es la que comúnmente ha girado en torno a las manifestaciones trasgresoras de actos delincuenciales. La locura ha sido estigmatizada y asociada a los actos más aberrantes y violentos de criminales despiadados, sin embargo, la imagen del loco no siempre estuvo asociada a la violencia de sus actos. Siguiendo las nociones pretéritas de la locura que aborda Michael Foucault, la historiadora María Cristina Sacristán indica que durante la Edad Media los locos fueron figuras activas del paisaje rural y de las ciudades. Esta época fue un momento en que los orates podían ser tolerados, alimentados y cuidados por su familia o comunidad, llevados a peregrinaciones a los santuarios en espera de un milagro que los curase o simplemente dejados a su suerte ${ }^{1}$.

El punto de quiebre se dio en el siglo XVI, cuando las sociedades del Antiguo Régimen, en el caso de la Corona española, asociaron a los locos con otros tipos sociales como los pobres, los mendigos y los enfermos. A raíz de esta unión, los locos empezaron a formar parte de la masa común de seres disminuidos o desvalidos cuya responsabilidad, cuidado, vigilancia y asistencia, a falta de profesionales o expertos en el tratamiento de la locura, quedaría relegada a la red social más cercana del sujeto desvalido $^{2}$. Esto no significaba que estuvieran bien atendidos, de hecho, los sometían constantemente por medio de la violencia cuando su "furia" o actos insensatos se desencadenaban.

Desde el siglo XVII, por razones muy diversas, los locos serían relegados de la comunidad o eliminados por medios insólitos, como entregados a los marineros para que los dejaran lejos en un destino incierto. Los locos pasaron de ser un grupo social tolerado a ser encerrados en establos como animales, recluidos en celdas de cárceles u hospitales, injustamente arrojados fuera de las ciudades ${ }^{3}$.

Sacristán tiene dos observaciones con respecto al imaginario social sobre la locura: la primera fue otorgarle al loco el estatus de un ser débil, carente de raciocinio y pobre, por lo que es un necesitado de ayuda; la segunda, que es un peligro para la sociedad por su actuar sin sentido en contra de la normalidad ${ }^{4}$. A estas nociones se le debe agregar el trato denigrante hacia el loco porque su existencia representaba la imagen de un ser vulnerable, frágil e indefenso, objeto de burlas, abusos y malos tratos; en su mayoría seres enfermos que a lo largo de la historia se quejaban de in-

1 María Cristina Sacristán, "La locura se topa con el manicomio. Una historia por contar", Cuicuilco 16, n. ${ }^{\circ} 45$ (abril de 2009): 165.

2 María Cristina Sacristán, “¿Quién me metió en el manicomio? El internamiento de enfermos mentales en México, siglos XIX y XX”, Relaciones XIX (1998): 204.

3 Sacristán, "La locura se topa", 165.

4 María Cristina Sacristán, "Entre curar y contener. La psiquiatría mexicana ante el desamparo jurídico, 1870-1944”, Frenia. Revista de Historia de la Psiquiatría 2, n. 2 (1 de enero de 2002): 63. 
sensatez, falta de juicio y de la incapacidad de razonar. Por ese motivo, se convierte en un peligro por la amenaza que significa para sí mismo y quienes lo rodean. Solo en casos de violencia, la única alternativa es la del sometimiento mediante el uso de la fuerza. Este acercamiento se fundamenta en el deber de protegerlo por su condición de enfermo, pero también por el derecho de defenderse porque significa una amenaza contra el orden social.

En ese sentido, este artículo será guiado bajo la siguiente pregunta: ¿cuál fue la percepción social que hubo sobre los delitos cometidos por Roque Londoño y Lucía Ardila en los años de 1809 y 1822 ?

Este trabajo pretende ofrecer al lector un análisis de los testimonios de quienes estuvieron presentes en los delitos cometidos por Roque Londoño y Lucía Ardila, dos neogranadinos que manifestaron presuntamente su locura a través de actos delictivos como robo, agresión, infanticidio, entre otros. Antes de presentar los casos, se realizará una caracterización social de la locura, paralelo con un abordaje al concepto de delito, esto con el fin de acercarnos al imaginario social que existía sobre las personas con enfermedades mentales durante el siglo XVIII e inicios del siglo XIX.

Las fuentes documentales a utilizar son la solicitud de aprehensión contra Roque Londoño del año de 1809 en la parroquia de La Mesa, emitida por su hermano Juan de Dios Londoño. También estudiaremos la causa seguida contra Lucía Ardila por el delito de infanticidio contra sus dos hijos en el año de 1822 en la ciudad de Vélez. Estas fuentes se encuentran ubicadas en el Archivo General de la Nación (AGN), en la sección de Colonia, Real Audiencia y sección República, Asuntos Criminales. Este trabajo investigativo se encontrará dividido en tres secciones: en la primera parte, un análisis del concepto de locura y delito; la segunda y tercera parte se destinarán para analizar las causas delictivas relacionadas con locura anteriormente mencionadas.

Este artículo es una reflexión de mi trabajo de grado: "Ningún loco sabe lo que hace. Imaginarios sociales sobre la locura en las provincias de Popayán y Santafé, 1800-1839".

\section{"Ningún crimen tiene fundamentos razonables"}

La locura ${ }^{5}$ representó el tenue hilo casi invisible entre las buenas costumbres y los actos pecaminosos. Fue práctico separarlas de la realidad cotidiana comúnmente aceptada de la versión discordante de algunos seres humanos que moraban lejos de lo sensato. Su existencia casi siempre ha representado un problema, por lo que se ha hecho necesario crear instituciones y sistemas de información que intentan darle no

$5 \quad$ Para este artículo, el concepto de locura se entenderá como la privación de la razón, la incapacidad de entendimiento y la falta de juicio, una interpretación social muy común en el siglo XVIII. Olga Marcela Cruz, "Expresiones de la locura en el Virreinato de la Nueva Granada durante el siglo XVIII", Frenia XI (2011): 48. 
solo una explicación, sino también contener sus expresiones, administrar y eliminar su aparición. Incluso los involucrados que han dejado una huella entre la sociedad por su inestabilidad, convirtiéndolos en amenazadores del frágil orden social ${ }^{6}$.

La historiadora Olga Marcela Cruz en su tesis "Quien de Locura enferma, tarde sana" nos presenta el concepto de locura como una dualidad, pues su estudio se centra en la diversidad de sus interpretaciones:

La locura existe en oposición a la cordura. En ese sentido, la locura no se trata de un concepto unívoco, como quiera que su interpretación atañe no una sino varias concepciones sobre la mente, el cerebro, el cuerpo, la enfermedad; en suma, diversas versiones sobre la vida humana. Además, la locura por su propia naturaleza cuestionaba el orden establecido: como enfermedad, el orden fisiológico del cuerpo; como trastorno mental, la razón; y como desviación cultural, la religión. Al historiar la locura y sus nominaciones, se puede acceder a las formas como los hombres se percibían a sí mismos y como se concebían en términos de seres humanos que deben cohabitar en espacios y épocas específicas buscando su convivencia ${ }^{7}$.

A pesar de lo variable que es el concepto, existe un consenso entre lo disímil que es encontrar el origen de sus manifestaciones. La locura puede producirse por el desborde de sentimientos, por un desequilibrio humoral, por el fanatismo religioso, por la brujería o la posesión, por la obsesión que produce una actividad o puede ser la suma de todas las experiencias anteriores ${ }^{8}$.

No obstante, en el periodo colonial la mayoría de ocasiones estar loco implicaba encontrarse en el grupo de los ociosos, incapaces de trabajar productivamente; se relacionaba a las personas con problemas mentales con aquellas de un grupo amplio conformado por pobres, huérfanos, ancianos, alcohólicos, prostitutas, desprotegidos morales y menesterosos. Generalmente, estas personas se aglomeraban en los mismos lugares y muy rara vez se diferenciaban entre ellos. Su incapacidad y la pobreza que los afligía era su única característica común 9 .

Juan Carlos Jurado nos indica que las personas pobres carecen de los tres pilares esenciales sociales de la modernidad occidental: oficio, renta y destino. En un sentido amplio, no tener con que subsistir o ingresos seguros, significaba la imposibilidad de vivir en condiciones dignas. No tener una residencia fija, tuvo un doble significado:

6 Andrew Scull, "La locura desatada", en La locura: una breve introducción (España: Alianza editorial, 2013), 16.

$7 \quad$ Olga Marcela Cruz, “'Quien de locura enferma, tarde sana': la locura en el Virreinato del Nuevo Reino de Granada (1750-1810)" (tesis de doctorado en Historia, Universidad de los Andes, 2018), 62.

$8 \quad$ Ibid., 63.

9 Andrew Scull, "V. Manicomios y loqueros", en Locura y civilización: una historia cultural de la demencia, de la Biblia a Freud, de los manicomios a la medicina moderna., primera, Locura y civilización (México: Fondo de Cultura Económica, 2019), 128. 
no pertenecer a una comunidad era equivalente a no ser identificado por una familia o una casa en particular, este era el castigo al que estaban condenados por el desarraigo social que les costaba identificarse; al no poder sentirse reconocidos, se les dificultaba acceder a una vida "cristiana y civilizada".

La tercera característica fue no tener un destino, lo que era el resultado de los dos aspectos anteriores. No tener una residencia fija y renta le imposibilitaban al loco no tener una definición clara de valores. Su condición estaba a merced de cualquier camino y sus costumbres se trastocaban constantemente ${ }^{10}$.

Al encontrarse al margen de la sociedad moderna, los locos quedaron sin un rol social, lo que implicó nuevas concepciones que buscasen no solo invisibilizar su existencia, también eliminarla si fuese posible. Lo interesante en este punto es observar la evolución del sector dominante que procedió a perfeccionar sus técnicas de control y sometimiento ${ }^{11}$. Si bien lo expresó Foucault, cambió paulatinamente el trato hacia los insensatos. En este ideario, ellos no tenían la total culpabilidad de sus acciones porque sencillamente siempre se encontraban privados de la razón. Estos sujetos constantemente se saltaban los modelos impuestos de conducta, no lograban contenerse e incluso su aparato psíquico no estaba del todo constituido para introducirse en el proceso civilizatorio. Este proceso es iniciado en la edad de la crianza, donde se inculca a los individuos que la regulación debe ser cada vez más estricta y diferenciada de los comportamientos poco honorables, en donde se enseñan hábitos que deben ser casi que automáticos, como si todo el tiempo estuviese bajo una coacción propia de la que no puede liberarse, aunque lo quisieran conscientemente ${ }^{12}$.

Algunas de las herramientas de control para contener a los enfermos mentales fueron las cárceles, los hospitales y los manicomios ${ }^{13}$. Estos espacios son un ejemplo de que la idea de confinamiento es un acto estatal de custodia que no solo contempló el secuestro físico, representó también la degradación de la locura en sí misma. El

10 Juan Carlos Jurado Jurado, "Vagos, pobres y mendigos. Hacia una sociología del problema”, en Vagos, pobres y mendigos. Contribución a la historia colombiana, 1750-1850, editado por César Hurtado (Medellín: La carreta Editores, 2004), 43

11 La caridad no era solamente una estrategia de salvación individual, también involucraba la idea de controlar a la población pobre: "primero, la idea de sacrificio — principalmente Dios - o como un acto de gracia del dador. Segundo, las donaciones son símbolos de prestigio que implican subordinación en quien los recibe. Tercero, quien recibe un obsequio adquiere una obligación, por tanto, la donación sirve como método de control social-". Edward Palmer Thompson, Agenda para una historia radical, Josep Fontana (director), Historia y teoría (España: Crítica, 2000), 30.

12 Michel Foucault, "El nacimiento del asilo", en Historia de la locura en la época clásica II (México: Fondo de Cultura Económica, 1990), 39.

13 Rosselli, a quien se le acredita ser el pionero del estudio de la locura en Colombia, aclara que no se hallan datos que especifiquen que durante la Colonia existieran manicomios en el país. Al parecer, los enfermos mentales eran recluidos en celdas especiales dentro de los hospitales de las ciudades, de lo contrario, a falta de instituciones hospitalarias, estarían encerrados en cárceles. Humberto Rosselli, "Capitulo II. Noticias coloniales sobre patología y terapéutica mental", en Historia de la Psiquiatría en Colombia, vol. I (Editorial Horizontes, 1968), 22. 
confinamiento masivo consistió en el encierro de locos y pobres a manos de los partidarios de la ética laboral. Durante su estadía, los recluidos eran obligados a trabajar a fin de anular su modo de vida ociosa, totalmente opuesta al modelo de civilización inspirado en la exaltación de valores como el esfuerzo y el trabajo. Es así como, la base de la investigación sobre la locura se articulaba a los nuevos parámetros culturales de la sociedad en pleno avance de la burguesía con sus incontables efectos, en razón de lo cual empezó a asociársele a condiciones de pobreza, improductividad e inadaptación social, convirtiéndola así en un problema moral de dimensiones éticas. Por lo anterior, el historiador Roy Porter infiere que la locura quedó confinada bajo una actitud de represión y control ${ }^{14}$.

El manicomio cumplió distintas funciones para asegurar la integración de la sociedad en momentos de inestabilidad, esencialmente era un dispositivo al servicio de las exigencias de la sociedad precapitalista porque el interés siempre fue combatir la ociosidad y la falta de productividad. De ahí el sentido práctico del manicomio como un territorio destinado al cuidado, tanto en el sentido de atender, como en el de vigilar a peligrosos y diferentes. Paso previo al sentido científico, que vendría como el territorio para la explicación que mostraba a este tipo de sujetos como portadores de pensamientos, emociones y raciocinios amenazantes para la sociedad ${ }^{15}$.

Otro instrumento para el control de población de enfermos mentales fue la petición de internar a los locos aunque estos no hubiesen cometido delito alguno. Este mecanismo se fundamentaba en la doctrina de la defensa social, basada en la idea de que todo individuo es responsable de sus actos por el hecho de vivir en sociedad y que esta tiene derecho a defenderse y protegerse de quien represente una amenaza para su sobrevivencia, tanto si tuvo la capacidad de reconocer la licitud de sus actos como si no ${ }^{16}$. Este cambio que se da para mediados del siglo XIX es decisivo para la interpretación de la locura como un problema social. El poder judicial y los alienistas optarían por culpabilizar y criminalizar la locura, ya que los locos, al estar en medio de la población marginalizada, serían injustamente asociados con criminales. En este preciso momento, la locura tendería a volcarse a la imagen clásica del loco que en párrafos atrás referenciábamos.

La relación entre la locura y el delito se sitúa en el momento en que la sinrazón se encontraba desde el siglo XVII reducida al silencio. Esta unión reaparece, no como el simple hecho de segregar a una población de personas, sino como un discurso de marginalización y estereotipos. El sujeto loco, bajo su grado de exclusión, entra en el espectro de una persona "peligrosa" por el hecho de que es ajeno a la razón ${ }^{17}$.

14 Roy Porter, Breve historia de la locura, 1.a ed., Colección Noema (México: Fondo de Cultura Económica, 2003), 75

15 Sacristán, "La locura se topa", 166.

16 Sacristán, "Entre curar y contener", 78.

17 Carolina Miranda, "Marginalidad y exclusión en América Latina: el caso de los locos en la Casa de Orates 
De esa manera, en los primeros años de la República, la policía de la provincia de Cundinamarca tenía la orden de impedir que "anden por plazas, calles y caminos públicos locos o personas furiosas", esto con la intención de realizar una limpieza de sujetos "indeseables", reteniéndolos en sus casas o en los hospitales. Entre los años de 1820 y 1827, estas personas eran subidas a la "jaula de San Juan de Dios", una carroza enrejada que recorría las calles en medio de los curiosos, quienes atemorizaban y amedrantaban al pobre enfermo mental enjaulado ${ }^{18}$.

Es así como, al leer a Germán Colmenares, consideramos que los delitos, su tipología, descripción y la frecuencia con la que se juzgaban, revelan la naturaleza íntima de la sociedad: sus temores, sus tabúes y, sobre todo, las limitaciones que encontraban en el desarrollo de su individualidad ${ }^{19}$. La sociedad repudiaba con más firmeza lo que trasgredía el comportamiento social aceptado. De esa forma, los delitos son todas aquellas acciones que se conciben como una infracción a una conducta típica descrita en una norma jurídica. Solo estas normas tienen la potestad de estipular las penas a las infracciones, las cuales deben materializarse con la protección de los derechos de quienes se encuentran involucrados en la litis (litigio judicial). El delito en la República, según Barbosa Delgado, corresponde a una acción voluntaria e intencionada de la violación de la ley. Para esta época, el hombre era considerado como un ser libre, pero si infringía la disposición penal y se encontraba cometiendo acciones en contra del establecimiento, era sujeto de una sanción. Esa figura era la consecuencia del delito y existía tanto en el sistema penal colonial, como en el sistema republicano ${ }^{20}$.

En ese sentido, los castigos a las acciones delictivas tenían un doble propósito: por un lado, servían para poner en su lugar a "sujetos indeseables", satisfaciendo una necesidad social de exclusión ${ }^{21}$. Por otro lado, debía ser beneficioso para el delincuen-

de Santiago, 1852-1928”, 2, accedido 21 de octubre de 2019, https://www.academia.edu/32714966/ Marginalidad_y_exclusi\%C3\%B3n_en_Am\%C3\%A9rica_Latina_el_caso_de_los_locos_en_la_ Casa_de_Orates_de_Santiago_1852-1928.

18 Jairo Gutiérrez Avendaño, Locura y sociedad. Alienismo tardío, psicopatología e higiene mental en la modernidad colombiana 1870-1968 (Envigado: Institución Universitaria de Envigado, 2019), 53-54.

19 Germán Colmenares, "La ley y el orden social: fundamento profano y fundamento divino", Boletín Cultural y Bibliográfico 27, . $^{\circ} 22$ (1990): 8.

20 Francisco Roberto Barbosa, Justicia: rupturas y continuidades. El aparato judicial en el proceso de configuración del Estado-Nación en Colombia. 1821-1853, vol. 1, Taller y oficio de la historia (Bogotá: Universidad Javeriana, 2007), 204.

21 En Chile hubo dos modelos de presidio durante la primera mitad del siglo XIX: el modelo duro e implacable heredado de la Colonia y el de la institución prevista para el trabajo público, un modelo propio de la visión decimonónica disciplinaria. Tanto las autoridades borbónicas como las republicanas implementaron varios dispositivos de control social que se reflejaran en el aumento de hospicios, escuelas de trabajo, hospitales y cárceles; el objetivo siempre era someter a todos los criminales. Los dos modelos se basaban en la exclusión social de los criminales, esa noción de aislamiento va más allá de la separación y marginalización, representa la eliminación de todos los aspectos cotidianos y simbólicos que tiene una persona en la sociedad. Miranda, "Marginalidad y exclusión en América Latina", 2. 
te, quien debía recomponerse de sus delitos, aprender a comportarse en sociedad y sobre todo no reincidir. Desde un punto de vista práctico, en una sociedad en donde el prestigio y el honor personal estaba a la vista de todos, un proceso por delito, así se tratase de algo insignificante, involucraba el juicio de toda una vida, igualmente se observaba toda una vida de comportamientos. Los delitos eran desafíos permanentes al orden socialmente establecido, basado en la moral cristiana y en la ética laboral ${ }^{22}$.

Debemos aclarar que los locos no eran contemplados en los códigos penales para inicios de siglo XIX, por lo tanto, no había una tipificación estatal que los pudiera juzgar. El primer lugar en donde se manifestaba la locura y se afrontaba era en la privacidad del hogar. El diagnóstico y tratamiento de la enfermedad se llevaba también en el ámbito doméstico; las autoridades solo intervenían cuando el loco se salía de control, cuando había un escándalo familiar a raíz de los problemas ocasionados por el enajenado mental y se viera afectado el orden social ${ }^{23}$.

No obstante, la atención estatal que les podían brindar era insuficiente. La falta de un marco teórico para la protección o enjuiciamiento de personas locas significó un gran lío para los jueces, por lo menos en los dos casos que estudiaremos. La única forma de enjuiciar a un loco era mediante un peritaje médico, a falta de estos especialistas. Quienes certificaban la locura del delincuente eran quienes estuvieran al lado del enfermo durante casi toda su vida. El juez y el fiscal representaban la moral y la ética, las buenas costumbres y los valores que se encarnan en la sociedad, por lo tanto, sus acciones debían ir encaminadas a la representación social de su comunidad. Estos dos agentes sociales responden a una suerte de pertinencia social ${ }^{24}$, sus decisiones legitiman lo socialmente establecido.

\section{Roque Londoño, el loco frenético}

El 1 de agosto de 1809, Juan de Dios Londoño le solicita al alcalde de la parroquia de San Antonio de la Mesa ayuda para aprehender a su hermano Roque Londoño, quien habría realizado múltiples atentados a los esclavos de su hermano Juan de Dios, daños en el trapiche de la hacienda de su familia y robos a los vecinos. Miedo, pánico y terror, es el legado de Roque Londoño. Sus actos violentos reflejan la imagen clásica del loco, no se podrá saber si en su vida fue juzgado por sus delitos, porque no hay causas seguidas contra sus crímenes, lo que se podrá conocer en este documento es todos los inconvenientes que le causó a su hermano, a sus vecinos, a la comunidad de La Mesa y a los pobres esclavizados que aguantaron sus ataques de locura frenética.

\footnotetext{
22 Colmenares, "La ley y el orden social", 6.

23 Cruz, "Quien de locura enferma", 15.

24 Marcos Fernández, "La explicación y sus fantasmas. Representaciones del delito y de la eximición de responsabilidad penal en el Chile del siglo XIX", Revista de Historia Social y de las Mentalidades 4 (2000): 120.
} 
El día 20 de julio de 1809, Juan Eugenio Londoño, le escribió a su amo Juan de Dios Londoño desde la hacienda la Zaragoza — cercana a la parroquia de La Mesa- . $\mathrm{Su}$ carta es un llamado de auxilio porque su vida se encontraba expuesta ante los ataques de Roque, sus palabras fueron las siguientes: "participo a su merced como mi amo don Roque cada vez es lo mismo, o peor, con decirle a su merced que mi vida se halla expuesta, pues temo cuando me coge en el cuarto y me mata porque no le entrego dinero o les pega fuego a las casas" 25 .

A Roque no le bastó con hacerle daño a Juan Eugenio, también se inmiscuyó en la parroquia del pueblo para hurtar una caja de polvos y un perfume del Padre. Unos días después se robó una vaca y la mató, el animal era propiedad del vecino Berrio Buitrago. También golpeaba a los esclavizados con palos y le prendía fuego al patio. La calamidad tocaba a la puerta de la hacienda Zaragoza si no se controlaban los actos desmesurados de Roque. Quien podía prevenir tan terrible destino era su hermano Juan de Dios Londoño, porque era el único que tenía el control sobre Roque. Juan Eugenio le pidió sacar al loco de la hacienda y del pueblo lo más pronto posible, así fuese con engaños; esta carta sugiere que sea encerrado lo más pronto posible: "procure mandarle la orden al alcalde de la parroquia para que aprese y se lo lleven al hospital o ver si manda un comando que pueda conseguir soldados, porque aquí no hay quien se le atreva" ${ }^{\prime 26}$.

A este llamado se le agrega el otro pedido de auxilio proveniente de la esclavizada Petrona Bernal, quien le envía una carta el día 27 de julio de 1809:

Le aviso a vuestra merced como el señor Don Roque vino en días pasados, y me llevó un pañuelo grande de montar a caballo, y desde ese día me he estado guardando de él escondiéndome, $\mathrm{y}$ he abandonado mi casa, e hijos, perdiéndome por esta causa, mis chichas y demás cosas. El lunes en la noche vino a deshoras, y sin reparar que había gente, me atropelló fuertemente queriéndose acostar conmigo, me cogió entre la cama, y me dio dos puños, a los repetidos gritos que yo daba [ilegible] la gente y pude escapar con uno de mis hijos en los brazos, salí fugitiva a buscar refugio en la vecindad, quedando todas las puertas abiertas ${ }^{27}$.

Como si fuera poco, Roque repartió las botellas de aguardiente y le robo los pocos cuartillos que recibió por la venta de pan, le "desquició" el cuarto, se le tomó la chicha y también repartió el alcohol de Bernal; se llevó cuatro fangos de tabaco y todos los días amedrantaba a la gente de la parroquia. Petrona le suplicó que le pagara las pérdidas ocasionadas por tan lamentables acontecimientos. Ella, una mujer que se

25 "Solicitud de aprehensión contra Roque Londoño, 1809" (Santafé, 1809), en Archivo General de la Nación (AGN), Sección Colonia, Real Audiencia, Sig. SC.50,1, D.32, f. 963.

26 Ibid., f. 963r.

27 Ibid., f. 965r. 
mantenía por su extenuante labor, le pidió a Juan de Dios que sacara a Roque de la parroquia cuanto antes.

Para que las autoridades decidieran capturar a Roque como lo sugieren las dos cartas anteriores, debían encontrarlo en las siguientes situaciones: embriagado vagando por las calles, que se encontrara participando de disturbios públicos o situaciones violentas, a partir de las cuales se le consideraba un sujeto peligroso. La tercera es por las causas iniciadas para resolver sucesión o repartición de bienes, esta medida requería de un juicio que declarase la incapacidad del enajenado ${ }^{28}$.

En Nueva Granada no existían leyes que obligaran a las familias a hacerse responsable del loco, sin embargo, para la comunidad era claro que quien debía responder por los daños causados eran sus parientes, en este caso, Juan de Dios debía hacerse responsable de los perjuicios causados a Petrona, quien sufrió de agresión física y la despojaron de su dinero, pero también perdía él mismo porque su hermano destrozaba su hacienda ${ }^{29}$.

Ahora bien, Roque de alguna manera fue atrapado y encerrado en el hospital San Juan de Dios de Santafé. Fray José Mariano Barreta, cuidador de los enfermos y presidente del hospital, diagnosticó a Londoño como "enfermo loco frenético". Su terapia se basaba en el encierro en jaulas y prisión en cepo para poderlo contener. De igual manera, se le suministraron algunos medicamentos que lo mejoraron un poco. Ante tan efímero alivio se le puso en libertad dentro del recinto, pero huyó del hospital tan pronto le fue posible. Barreta ordenó que lo atraparan y lo enviaran de nuevo al hospital porque era muy posible que recayera de nuevo en frenesí3 ${ }^{30}$.

Desesperado, Juan de Dios Londoño le escribe al alcalde de segundo voto de La Mesa, Josef Antonio Ugarte. En cada palabra escrita se observa la frustración de este hombre:

Que en mi hacienda de Zaragoza tenía a mi hermano Don Roque Londoño. Allí le acometió una locura que lo precipitaba a mil excesos: con un cuchillo en mano acometió a los negros, que intimidados se fugaron, y escondieron en los montes: en tales circunstancias lo cogí y traje preso al hospital San Juan de Dios de esta ciudad, donde se colocó en la jaula, con las presiones necesarias a su contención. Con los remedios que

28 Daniela Bassa, "Insania y justicia en el territorio nacional de la Pampa argentina (1880-1930)", Frenia 3, (2003): 57-58.

29 Un caso famoso fue el de la China Imperial. Durante los años de 1731 y 1908 dio muestra de su potencial de control cuando implantó un programa de registro y confinamiento de locos bajo "arresto domiciliario". Las familias que tuviesen bajo su seno a un alienado estaban obligadas a comprometerse a controlarlo bajo estricta vigilancia. La ley de este Estado culpabilizaba a los parientes en caso del suicidio o los homicidios que cometiera. Si la familia no podía demostrar que podía disponer de condiciones apropiadas para mantener asegurado al alienado, este se destinaba al encierro junto a otros criminales, por lo tanto, la familia se vio obligada a transformar su tradicional papel tutelar, adquiriendo responsabilidades de vigilancia y control. Sacristán, “¿Quién me metió en el manicomio?”, 211. 
se le aplicaron re estableció un poco, y salió fugitivo, como consta de la certificación del padre presidente que acompaño. Actualmente se halla en Zaragoza, de donde sale y va a las parroquias de San Antonio de la Mesa [...] todos los días comete los atentados que se me avisan en las tres cartas que exhibo ${ }^{31}$.

Juan de Dios describe a Roque como un hombre de fuerzas extraordinarias que tiene intimidados a todos los vecinos, pues en cuatro ocasiones ha prendido fuego a los trapiches y casas de la hacienda; ya no tiene control sobre ninguno de los actos de su hermano y cree que "un loco nada respeta y puede cometer mil crímenes, de que no es responsable por obrar sin razón" 32 . Londoño le solicitó al alcalde que capturara a su hermano en el lugar que se hallara y procediera a remitirlo preso al hospital para que lo curaran, él pagaría todos los costos que fueran necesarios para cumplir con esa labor ${ }^{33}$.

Como lo sugirió Juan Eugenio Londoño, las dos posibilidades de controlar a Roque consistían en el encierro. A pesar de que no tengamos fuentes que demuestren la existencia de sitios especializados para el confinamiento, como por ejemplo el manicomio, la idea de curación mediante la reclusión fue una medida generalizada tanto en Europa como en América, tanto para las personas de élite como para las personas que no lo eran. La noción de encierro con fines curativos y de vigilancia fue sin duda la forma más común de encerrar a quienes necesitaban de ayuda y que significaban un peligro para la comunidad.

Encerrar a una persona es un método que previene cualquier daño y perjuicio, pero también demuestra la capacidad de vigilancia; es al mismo tiempo un procedimiento correctivo. Este fue el método más utilizado durante gran parte del siglo XVIII, durante mucho tiempo se creyó que las personas locas debían estar encerradas cuando significaran un peligro para la sociedad.

Los términos loco furioso o frenético son bastante inexactos, y dan muestra de que no había un conocimiento sobre las enfermedades mentales. Atendiendo a la definición que encuentra Olga Marcela Cruz en sus estudios de locura en la Nueva Grana$\mathrm{da}$, se refiere al loco furioso como "el enojado colérico, que con furia y sin considerar lo que hace, se arroja a hacer algún desatino sacándole de su juicio la ira”. En ese sentido, es el que actúa llevado por furor, que no es contra cosa que "locura confirmada, enajenación total de la mente, ira, rabia, cólera y enojo", la preocupación principal en el tratamiento de este loco es asegurarlo y evitar que pueda hacer daño a otros ${ }^{34}$.

El alcalde ordinario de La Mesa, Salvador Machado, responde a la solicitud de auxilio para la aprehensión de Roque Londoño por ser un loco frenético que pone en riesgo a la comunidad de la hacienda Zaragoza y a los vecinos. Se niega a brindar

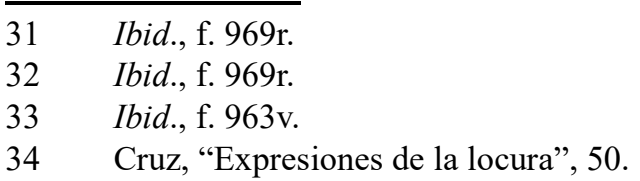


ayuda a tan necesaria causa. La gente con la que contaba se encontraba ocupada en la construcción de un puente para el bien del público. Además, eran personas de un carácter "pusilánime" que tan solo tienen fuerzas para terminar tan tediosos trabajos y para cumplir con sus obligaciones. Era gente tan cobarde y tímida, que "no se encontraban en las condiciones de detener a un hombre tan terrible como Roque. Además le temían por sus constantes amedrentamientos, preferían huir antes que enfrentarlos, escapaban de sus casas dejando todo atrás" ${ }^{35}$.

El alcalde Salvador Machado había escuchado de todos los crímenes que había perpetrado Roque Londoño, no obstante, no entendía por qué Juan de Dios le pedía ayuda, pues era un hombre hacendado, pudiente, con vecinos y esclavos suficientes para atrapar a su hermano sin mayor problema, mientras que la vecindad solo contaba con unos pobres hombres que se encargaban de construir el bien de todos ${ }^{36}$.

Ante la negación de asistencia, Juan de Dios Londoño le escribió al Cabildo de Santafé como última instancia de ayuda. Su carta recoge los testimonios de abusos de su hermano y expresa su inconformidad por la respuesta negativa del alcalde de La Mesa. Londoño dice que sus haciendas se encuentran expuestas a la ruina y en cualquier momento Roque puede matar a alguien llenando de luto a su familia. Esta causa culmina con la disposición de aprehensión de Roque Londoño por parte de un funcionario del Cabildo de Santafé ${ }^{37}$.

Según Colmenares, solo en el perímetro de las ciudades existía un sistema efectivo de jerarquías sociales, el ejercicio de control y castigo hacia los criminales en la mayoría de los casos fue eficiente y contundente, todo lo contrario en las áreas alejadas de la centralidad. En los antiguos pueblos coloniales la aplicación de la justicia y la efectiva presencia del Estado significó un problema, pues no poseían el control sobre sus instituciones fuera de las urbes ${ }^{38}$. Por ese motivo, el hacendado Londoño tuvo que apelar a una instancia que tuviese la capacidad de responder ante su pedido de auxilio y reprochara la actitud desinteresada del alcalde.

Para finalizar este caso, tomaré nuevamente una de las reflexiones propuestas por Olga Marcela Cruz en su estudio sobre el caso de Roque Londoño. Ella comenta que los testimonios de los sujetos que convivían con Londoño estaban cargados de angustia y dramatismo. Los vecinos, las autoridades y el hermano de Roque pronunciaban reiteradamente el temor que les causaba la violencia propiciada por el furor de una locura incontenible, encarnaba los profundos temores de la sociedad

La conducta impulsiva, la piromanía, el acceso carnal violento, el robo, la agresión física y el homicidio. No se trataba únicamente, como bien lo relatan los testigos

35 "Solicitud de aprehensión contra Roque Londoño, 1809”, f. 971r.

$36 \quad$ Ibid., f. $971 \mathrm{v}$.

37 Ibid., f. $972 \mathrm{r}$ y $972 \mathrm{v}$.

38 Colmenares, "La ley y el orden social", 
del caso en sus palabras, de que aquel personaje estuviera loco, sino de que "quería volvernos locos" [...] atentaba contra su cordura porque amenazaba el orden social que los regía ${ }^{39}$.

\section{Lucía Ardila y la luna ${ }^{40}$}

La causa seguida contra Lucía Ardila por el delito de infanticidio inicia en el mes de septiembre de 1822 en la ciudad de Vélez en la provincia de Pamplona. Quizás la comunidad reprochó por el resto de sus días a Lucía Ardila por el delito tan cruel y despiadado que cometió. Santiago Araujo, procurador de pobres ${ }^{41}$, defendió a Lucía. Ella, según su defensor, no lo hizo en su sano juicio, tampoco de manera deliberada; esta mujer se hallaba acometida por una especie de locura, por lo cual, carecía de razón y obró marginalmente sacrificando a sus dos hijos sin ningún motivo aparente. En su estado no podía actuar con malicia, por eso, como primer método de defensa, Araujo le ruega al alcalde ordinario de la ciudad de Vélez que la absuelva de su pena $^{42}$.

En cuanto a su delito, el infanticidio es un acto que ha motivado repulsión en todas las sociedades porque es una acción que se comete contra un ser humano incapaz de defenderse, un niño recién nacido o de pocos días de existencia. El malestar de toda la comunidad es mayor cuando el homicidio es perpetrado por la madre, una persona que le da vida a una criatura con tanto amor no puede ser quien se la quite ${ }^{43}$.

39 Cruz, "'Quien de locura enferma", 148-149.

40 La negligencia del alcalde provocó que la causa de Lucía Ardila fuese resuelta en Santafé, pero esta causa no ocurre en la jurisdicción de la capital neogranadina.

41 Es interesante observar que en la causa seguida contra Ardila quien la defiende es un procurador de pobres. La función de este abogado es defender a esclavizados en cualquier litigio en que se viera involucrado, sea de origen penal o civil. Esta figura era ampliamente utilizada en Chile durante la Colonia y los inicios de la República. Estos representantes velaban por la manumisión, la libertad de vientres y abogaban por los esclavizados en los excesos de fuerza de sus amos. Carolina González, "El abogado y el procurador de pobres: la representación de esclavos y esclavas a fines de la Colonia y a principios de la República”, SudHistoria 5 (2012): 87.

42 "Causa criminal contra Lucia Ardila por el delito de infanticidio, 1823" (Vélez, 1823), en Archivo General de la Nación (AGN), Sección República, Asuntos Criminales, Sig. Asuntos Criminales de la Repúblicos: SR.12,28, D.13, f. 463r.

43 El honor es una categoría presentada por Prada. Es sumamente importante para entender el imaginario social de las personas que reprochaban estos actos criminales. Esta cualidad hace parte de la moral del individuo, quien se contempla así mismo a través de los demás; el honor se relaciona con la reputación, la respetabilidad o la gloria, y se obtenía por medio del juicio de terceros frente a los cuales se pretendía ejercer una posición superior. El honor se maneja en el dominio de lo privado, ya sea internamente en el individuo, en su casa o en su familia, y se pone en evidencia en la vida pública. Esta autora sugiere que el honor también era un mecanismo de represión social y jurídica - las dos podían operar al mismo tiempo-, lo fundamental era la censura social. Cuando los vicios privados eran de conocimiento público, se impulsaba una campaña de deshonor contra la familia. Jhoana Prada, "Infanticidio: perspectiva comparada y aportes bibliográficos de Europa y América Latina. (Mérida, Venezuela 1811-1851)", Anuario Hojas de Warmi 17 (2012): 4. 
En estos delitos tan bochornosos, el escándalo era un medio de represión social. Poseía la capacidad de convertir en hechos sociales conductas privadas, incluso las más íntimas. En esta expresión confluyen los motivos ideológicos de la Iglesia con los valores que el Estado buscaba sostener. En el escándalo recae el frágil equilibrio de una sociedad que se valía de las apariencias. La estabilidad social y política obligaba a que ningún acto infringiera los comportamientos morales que se imponían por un orden jerárquico. Esta categoría es la prueba del ejercicio de control de las conductas, pues era un deber colectivo denunciar las conductas deshonestas, por eso, el chisme era un auxiliar de la justicia ${ }^{44}$. Prosiguiendo con el caso, el fiscal presenta sus argumentos el día 12 de junio de 1823:

Que anqué el padre, marido y otros no asegurasen que Lucía Ardila se enloquecía en los novilunios y menguantes, casi no podía presumirse otra cosa vista de que, sin indicarse el menor motivo, ella ha tenido la prematura serenidad de expresar sus propios hijuelos: acción que no teniendo semejante entre las mismas fuerzas, es por ellos más bien, que nadie se atreverá a atribuirle sino el furor de una loca; más habiendo de hallar del modo loca fuera de sus opiniones particulares y si apoyo que el de las leyes y el proceso, habrá de manifestar, que Lucía Ardila por el proceso y las leyes no puede juzgarse insania el día del espantoso crimen que con sus manos hizo, primero se verá que en los autos no consta su insania, y después de ellos [ilegible] cordura en aquel día ${ }^{45}$.

Aunque la familia no tuviese la certeza de que Lucía enloqueciera en los novilunios, los testigos afirmaban que en los días antes y después del primer cuarto de luna, ella enloquecía. Los declarantes no certificaron que en el crimen Ardila se hallara loca, tampoco especificaron cuáles eran las manifestaciones de locura de esta mujer.

Para el fiscal no era seguro que la supuesta locura que acometía a Ardila fuera la razón por la cual acribilló a sus hijos. Su intención era juzgar a esta mujer como lo ordenaban las leyes, pero se detuvo porque las mismas no contemplaban sanciones para las personas que se hallaban locas. Ni para los testigos ni para el fiscal era seguro que esta mujer se hubiera hallado enajenada días antes del atentado. Tampoco es presumible que su marido se ausentara dejándola sola con sus hijos. El testigo Andrés Ramírez asegura que Ardila "no estaba ebria ni loca, y se funda que hablaba como sana" ${ }^{\prime 4}$. Cuando interrogaron a Ramírez, Lucía era una mujer que gozaba de libertad y no tenía prisión alguna, a pesar de que varias personas presenciaron su locura en los momentos previos al novilunio durante todos los meses. En el minucioso análisis del caso, el fiscal estudió las fechas del hecho infanticida y las cotejó con el calendario y las fases lunares, y estableció que el 17 de septiembre de 1822, fecha en la que se

$44 \quad$ Colmenares, "La ley y el orden social “, 7.

45 "Causa criminal contra Lucia Ardila por el delito de infanticidio, 1823", f. 465v.

46 Ibid., f. 466r. 
cometió el terrible atentado, era un día alejado del novilunio, entonces debía de estar sana de mente en ese momento ${ }^{47}$. El día 18 de octubre, el juez dijo lo siguiente:

Y que este día ella manifestó salud, y el juez no advirtió algún síntoma de demencia, pues de otro modo se hubiera abstenido de proceder. Luego de los autos resulta que Lucia Ardila estaba cuerda el día en que dio muerte a sus hijos así debería juzgarse, si fuera una cosa evidente que solo en los días de la luna se dementaba esta mujer como lo declaran los testigos; pero como ellos pudieron expresarse, por pura reflexión, por ignorancia u otra cosa, es materia tan grave sería conveniente preguntarlos sobre si solamente en la idea de la luna padecía la Ardila el ataque de furor, si están cierto de ello. Por qué razón, o si no están muy seguros, ha podido padecerlo en otro estado o punto del mes ${ }^{48}$.

La locura en el siglo XVIII se interpretó como un fenómeno relacionado con la naturaleza, es decir, las repercusiones naturales tenían consecuencias importantes en las manifestaciones de las enfermedades mentales. Esta enfermedad estuvo bajo la lupa de la interpretación astrológica, la influencia de los astros sobre el temperamento y las actitudes personales. Las fases lunares han sido asociadas a ciclos regulares, en la antigüedad se relacionó ampliamente con manifestaciones naturales y con los ciclos menstruales de las mujeres. El astro de la noche sirvió para ilustrar los cambios de humor y ánimo, así como ciertas formas de locura que eran transitorias ${ }^{49}$ pues, aparentemente, estaban conectadas con las mencionadas fases de la Luna. Estos días serían los más propicios para la aparición de ataques de locura, el aumento de la criminalidad o de otras manifestaciones mentales. Uno de los remedios más comunes para enfrentar esta enfermedad estacionaria fue la penitencia, la oración y el ayuno, muchos de los pacientes necesitaban la fuerza de Cristo más que las habilidades de médicos ${ }^{50}$.

Los estados de la Luna han sido sumamente importantes para el imaginario social: los campesinos cultivan dependiendo las fases lunares, los marineros observan las transiciones del astro para navegar, los artistas se han inspirado por las formas de la Luna. Entender la importancia natural de este fenómeno es entender el mundo de los "cuerdos", porque en estas asociaciones irradian sus creencias más profundas,

$47 \quad$ Ibid.

$48 \quad$ Ibid., f. 467 r.

49 "La locura había tomado forma en el Occidente cristiano desde la Edad Media [...] para el caso de las manifestaciones 'rítmicas' de la locura, es decir, aquellas que sobrevenían cada cierto ciclo lunar. Así, mientras algunas teorías explicaban, por ejemplo, la influencia de la Luna en la epilepsia por una venganza de Selene. También se propusieron 'hipótesis naturales', como aquella que afirmaba que la luna llena calentaba la atmósfera que rodea la Tierra y por ello derretía el cerebro provocando un ataque". Cruz, "'Quien de locura enferma”, 139.

50 Rafael Huertas, "Lunáticos y melancólicos. Humores, vapores y enfermedades de los nervios en la Edad Media”, en ¿Qué sabemos de? La locura., 2.a ed., ¿Qué sabemos de? (España: Catarata, 2014), 56. 
ideas que se han heredado durante mucho tiempo. En Nueva Granada, la pervivencia de tradición hipocrática era evidente, la asociación entre las enfermedades con las condiciones de los cosmos como los "puntos afirmativos" (luna nueva y cuarto creciente), los cuales tenían mayor influencia sobre la locura, distinto a los "puntos negativos" (luna llena y cuarto menguante) que tenían una influencia mínima ${ }^{51}$. Concebir la enfermedad de esta manera resultaba arcaico para muchos médicos europeos. Para el fiscal que intenta corroborar la locura de Ardila, aunque no estuviera confiado de los testimonios de los testigos, en su interior era posible enloquecer durante el novilunio, por eso decide mandar a suministrarle los remedios necesarios para evitar cualquier ataque de locura de esta mujer.

Cruz Montalvo menciona que durante mucho tiempo se pensó que el ciclo menstrual producía una locura particular en las mujeres, el origen de este mal estaba en el útero, que irritaba e infectaba el cerebro, los nervios y los músculos ${ }^{52}$. Socialmente se han construidos estereotipos alrededor del género, en ese sentido, hay enfermedades mentales que han sido asignadas a los hombres y otras distintas a las mujeres. La histeria fue un rasgo asignado al ciclo menstrual y, de forma despectiva, se creía que esta enfermedad se manifestaba por el furor del escándalo, la melancolía y la insensatez ${ }^{53}$.

Con el interés de conocer a profundidad los comportamientos de esta mujer antes y después del asesinato, los ministros Tobar y Marques, el día 8 de julio de 1823, crearon un nuevo cuestionario para que los testigos respondieran:

1. ¿Qué hizo Lucía Ardila cuando la hallaron después de haber matado a sus dos hijuelos? ¿Estaba oculta o pretendía esconderse? ¿Intentó resistir, manifestó algún temor o sobre salto? ¿Qué expresión profirió cuando la llevaron presa? ¿Dio alguna muestra de furor, de demencia o sentimiento?

2. ¿La enfermedad que la acometía era periódica y solo aparecía en la misma estación de la Luna? ¿Qué acciones manifestaba cuando se excedía en sus comportamientos? ¿Cuánto le duraban esas expresiones de locura? ¿La enfermedad la afectaba de improvisto? ¿Cuando pasaba esta fase lunar quedaba perfectamente buena?

3. Desde que se encuentra presa no da señales de locura, entonces, ¿en qué términos, circunstancias, tiempos expresa malestares de locura?

4. ¿Lucía Ardila es de un temperamento pacífico o iracundo?

$51 \quad$ Cruz, "'Quien de locura enferma", 139.

$52 \quad$ Ibid., 58.

53 Para conocer más sobre la relación entre la locura y el género, se recomienda a Javiera Contreras Tapia, "Enajenadas, poder y locura. Disciplinamiento de los cuerpos de mujeres internas en la Casa de Orates de Santiago y sus memorias psiquiátricas" (tesis de maestría en Estudios de Género y Cultura en América Latina, Universidad de Chile, 2015); María Angélica Ospina, "Con notable daño del buen servicio': sobre la locura femenina en la primera mitad del siglo XX en Bogotá", Antípoda. Revista de Antropología y Arqueología, n. ${ }^{\circ} 2$ (enero de 2006): 303-314, https://doi.org/10.7440/antipoda2.2006.15. 
5. Los que conozcan de su vida, comentarlo en su declaración.

6. ¿Encontraron el cuerpo de los niños desmembrados? ${ }^{54}$.

Lastimosamente, la causa seguida contra Lucía Ardila por el delito de infanticidio no tiene la sentencia de la Corte Superior del Distrito de Bogotá, al final del documento se anula la sentencia de absolución dada por el alcalde de Vélez por no contar con los testimonios suficientes para acreditar la locura de Ardila y por demorar la causa más de lo debido. Se le multa al alcalde y otras personas implicadas en el caso de Ardila por no acatar el debido proceso en la causa seguida.

Los ministros de la Corte del Distrito intentaron de distintas formas obtener la información precisa del caso de Lucía Ardila. Estos agentes debían garantizar que pagara por el delito que cometió o eximirla en el caso de que realmente estuviese enajenada mentalmente. El esfuerzo de peritaje realizado por los dos abogados aún era realmente básico. Para ese momento, las teorías sobre la conducta criminal y la certificación médica estaban basadas en los testimonios y las manifestaciones violentas del loco. Tan solo hacia finales del siglo XIX el peritaje médico cambiaría el interés de la sociedad colombiana por el fenómeno de la locura ${ }^{55}$.

\section{Consideraciones finales}

Para inicios del siglo XIX los locos no estaban contemplados en la tipificación delincuencial de la Colonia ni muchos menos de la República. Los sujetos enajenados mentalmente fueron previstos por primera vez en Colombia en el Código penal de 1837 como personas eximidas de cualquier culpabilidad en crímenes. Además, este código protegió a los locos de terceros que quisieran hacerles daño. Sin embargo, la relación medieval entre la locura y la inocencia era una medida de larga data, pues el derecho romano y el canónico estipulaban la incapacidad del loco para cometer delitos graves ya que lo comparaban como un ser menor de edad ${ }^{56}$. La presunción de inocencia no fue una medida creada en el país, pero su implementación la convirtió en el eje central de la inimputabilidad del loco en la defensa jurídica.

A lo largo de este artículo se presentó a la locura como objeto de estigmatización social, relegada al margen del proceso civilizatorio y negada a través del confinamiento en lugares como el manicomio. Esta perspectiva de control, si bien estuvo presente en la mentalidad de persecución estatal hacia las personas pobres, no fue tan drástica con la población de enfermos mentales. A pesar de los actos violentos que los locos

54 "Causa criminal contra Lucia Ardila por el delito de infanticidio, 1823", f. 468r y 468v.

55 Recomendamos revisar el trabajo de Vásquez Valencia, María Fernanda, "Degenerados, criminosos e alienados. Para uma história do conceito de degeneração na Colômbia, 1888-1950" (tesis de doctorado en Ciencias Humanas, Universidad Federal de Santa Catarina).

56 Cruz, "'Quien de locura enferma", 68. 
podían protagonizar, la visión social sobre este problema siempre procuró no culpabilizarlos por sus delitos porque la enajenación conlleva a manifestaciones violentas. No obstante, a pesar de que pretendieran eximirlos, también tenían el derecho de protegerse de ellos, como es el caso de Roque Londoño. Los esclavizados que trabajaban en la hacienda de su hermano reiteradamente le pedían auxilio a Juan de Dios, le imploraban que lo alejara de la comunidad porque sus acciones podían producir una tragedia que llenaría de luto a su familia.

En el caso de Lucia Ardila, podemos observar que el despiadado infanticidio hacia sus hijos presuntamente fue causado por un ataque de furor producido durante los novilunios de cada mes. Según su defensor, el ataque de esta mujer tan solo puede ser producido por un acto de furor. Los testigos del caso aseguraban que Ardila se hallaba dementada en los meses previos al delito, pero no pudieron certificar que durante el crimen se encontrase afligida por el furor.

Contrario a la visión científica que estaba en auge en el viejo continente, para el caso de las comunidades de La Mesa y Vélez, los imaginarios que existieron sobre la locura se acercan a las explicaciones más pretéritas, es decir, a las teorías sobre la defensa social y protección de locos, al igual que las teorías sobre manifestaciones naturales relacionadas con la locura producida por la Luna y sus fases. Los pensamientos ilustrados estuvieron presentes en los imaginarios sociales, pero eran más fuertes las creencias sociales sobre estos fenómenos: el loco es una persona que necesita de ayuda y puede pertenecer a la comunidad siempre y cuando no se comporte de forma violenta.

Finalmente, las personas cercanas a quien tenía un trastorno mental enfrentaron la locura a partir de sus propios marcos de comportamiento, es decir, la solución se presentaba en el transcurrir de su vida cotidiana y en la actitud del loco. Por lo general la contención y la curación dependían de las manifestaciones pasivas o violentas de los ataques de locura.

\section{Fuentes de Archivo}

Archivo General de la Nación (AGN), Bogotá- Colombia. República, Asuntos Criminales.

Archivo General de la Nación (AGN), Bogotá- Colombia. Colonia, Real Audiencia.

\section{Bibliografía}

Barbosa, Francisco Roberto. Justicia: rupturas y continuidades. El aparato judicial en el proceso de configuración del Estado-Nación en Colombia. 1821-1853. Vol. 1. Taller y oficio de la historia. Bogotá: Universidad Javeriana, 2007. 
Bassa, Daniela. "Insania y justicia en el territorio nacional de la Pampa argentina (1880-1930)". Frenia 3 (2003): 31-65.

Colmenares, Germán. "La ley y el orden social: fundamento profano y fundamento divino". Boletín Cultural y Bibliográfico 27, n. ${ }^{\circ} 22$ (1990): 3-19.

Contreras, Javiera. "Enajenadas, poder y locura. Disciplinamiento de los cuerpos de mujeres internas en la Casa de Orates de Santiago y sus memorias psiquiátricas", tesis de maestría en Estudios de Género y Cultura en América Latina, Universidad de Chile, 2015.

Cruz, Olga Marcela. "Expresiones de la locura en el Virreinato de la Nueva Granada durante el siglo XVIII". Frenia XI (2011): 47-66.

-. "Quien de locura enferma, tarde sana': la locura en el virreinato del Nuevo Reino de Granada (1750-1810)", tesis de doctorado en Historia, Universidad de los Andes, 2018.

Fernández, Marcos. "La explicación y sus fantasmas. Representaciones del delito y de la eximición de responsabilidad penal en el Chile del siglo XIX". Revista de Historia Social y de las Mentalidades 4 (2000): 105-30.

Foucault, Michel. "El nacimiento del asilo". En Historia de la locura en la época clásica II. México: Fondo de Cultura Económica, 1990.

González, Carolina. "El abogado y el procurador de pobres: la representación de esclavos y esclavas a fines de la Colonia y a principios de la República". SudHistoria 5 (2012): 81-98.

Gutiérrez, Jairo. Locura y sociedad. Alienismo tardio, psicopatología e higiene mental en la modernidad colombiana 1870-1968. Envigado: Institución Universitaria de Envigado, 2019.

Huertas, Rafael. "Lunáticos y melancólicos. Humores, vapores y enfermedades de los nervios en la Edad Media” En ¿Qué sabemos de? La locura., 2.a ed., 49-67. ¿Qué sabemos de? España: Catarata, 2014.

Miranda, Carolina. "Marginalidad y exclusión en América Latina: el caso de los locos en la Casa de Orates de Santiago, 1852-1928". Accedido 21 de octubre de 2019. https://www.academia.edu/32714966/Marginalidad_y_exclusi\%- 
C3\%B3n_en_Am\%C3\%A9rica_Latina_el_caso_de_los_locos_en_la_Casa de_Orates_de_Santiago_1852-1928.

Ospina, María Angélica. "'Con notable daño del buen servicio': sobre la locura femenina en la primera mitad del siglo XX en Bogotá". Antípoda. Revista de Antropología y Arqueología 2 (enero de 2006): 303-14. https://doi.org/10.7440/ antipoda2.2006.15.

Porter, Roy. Breve historia de la locura. 1.a ed. Colección Noema. México: Fondo de Cultura Económica, 2003.

Prada, Jhoana. "Infanticidio: perspectiva comparada y aportes bibliográficos de Europa y América Latina (Mérida, Venezuela 1811-1851)". Anuario Hojas de Warmi 17 (2012): 29.

Rosselli, Humberto. "Capitulo II. Noticias coloniales sobre patología y terapéutica mental”. En Historia de la Psiquiatría en Colombia, I:16-53. Editorial Horizontes, 1968.

Sacristán, María Cristina. "Entre curar y contener. La psiquiatría mexicana ante el desamparo jurídico, 1870-1944”. Frenia. Revista de Historia de la Psiquiatría $2, .^{\circ} 2$ (1 de enero de 2002): 61-80.

_. "La locura se topa con el manicomio. Una historia por contar". Cuicuilco 16, n. ${ }^{\circ} 45$ (abril de 2009): 163-88.

—_ "¿Quién me metió en el manicomio? El internamiento de enfermos mentales en méxico, siglos XIX y XX”. Relaciones XIX (1998): 203-33.

Scull, Andrew. "La locura desatada". En La locura: una breve introducción., 13-36. España: Alianza editorial, 2013.

- "V. Manicomios y loqueros". En Locura y civilización: una historia cultural de la demencia, de la Biblia a Freud, de los manicomios a la medicina moderna., Primera., 89-161. Locura y civilización. México: Fondo de Cultura Económica, 2019.

Thompson, Edward Palmer. Agenda para una historia radical. Josep Fontana (director). Historia y teoría. España: Crítica, 2000. 